\title{
Correction to: Indicators for site characterization at seismic station: recommendation from a dedicated survey
}

\section{Giovanna Cultrera $^{1}$ (D) . Cécile Cornou ${ }^{2} \cdot$ Giuseppe Di Giulio $^{3} \cdot$ Pierre-Yves Bard $^{2}$}

Published online: 1 July 2021

(c) Springer Nature B.V. 2021

\section{Correction to: Bulletin of Earthquake Engineering https://doi.org/10.1007/s10518-021-01136-7}

This correction is published as electronic supplementary PDF files namely MOESM1 and MOESM2 were overlooked during publication.

The article files have now been corrected.

Publisher's Note Springer Nature remains neutral with regard to jurisdictional claims in published maps and institutional affiliations.

The original article can be found online at https://doi.org/10.1007/s10518-021-01136-7.

\section{Giovanna Cultrera}

giovanna.cultrera@ingv.it

1 Istituto Nazionale di Geofisica e Vulcanologia, Roma, Italy

2 Univ. Grenoble Alpes, Univ. Savoie Mont Blanc, CNRS, IRD, Univ. Gustave Eiffel, ISTerre, Grenoble, France

3 Istituto Nazionale di Geofisica e Vulcanologia, L'Aquila, Italy 